\title{
Assessing the contribution of seismicity to the demand on ground support elements at LaRonde mine
}

\author{
G Sasseville Université Laval, Canada \\ M Grenon Université Laval, Canada \\ P Morissette Agnico Eagle Mines Ltd., Canada
}

\begin{abstract}
Seismic activity is known to affect the short- and long-term behaviour of mining ground support, yet the influence of seismicity on ground support demand is not fully understood. This paper quantitatively assesses the influence of various seismic parameters on the performance and degradation of ground support elements.

A large database was created using the LaRonde mine (Quebec, Canada) as a case study, which consolidates information on the history of the rock support of an entire mine sector comprising $18.5 \mathrm{~km}$ of drifts: type, installation date, and behaviour over time. This database was linked with the seismic event database available at the mine. Analyses identified various seismic parameters (i.e. large seismic events, number of seismic events, increase in apparent stress, b-value from the Gutenberg-Richter frequency-magnitude relationship, peak particle velocity, and energy radiated from the event) as precursory trends that may influence the performance and degradation of ground support elements.

A key finding is that the number of seismic events and their magnitude are contributing factors in controlling the demand on ground support. A high number of seismic events and high local magnitude event have frequently been recorded before observing degradation on ground support elements. Another important finding is that the demand on ground support cannot be explained entirely by seismicity; it is also controlled by other site factors.
\end{abstract}

Keywords: ground support, seismicity, database, degradation, demand

\section{Introduction}

Deep mining faces significant technical challenges such as a high likelihood of a large seismic event, defined as a dynamic stress wave generated by a failure within a rock mass (Hedley 1992). Mines under dynamic-loading conditions implement dynamic ground support systems as the last line of defence. The design of a ground support system must be sufficiently robust to hold, retain and reinforce the excavations throughout their service life. Dynamic support system design is usually based on professional experience and perceived performance rather than on an extensive understanding of the mechanisms that drive rock mass-support system interactions (Hadjigeorgiou \& Potvin 2011).

Several studies (e.g. Durrheim et al. 1998; Heal et al. 2006; Hedley 1992; Hudyma \& Potvin 2010; Kaiser \& Cai 2012; Kaiser et al. 1996; Morissette 2015; Potvin \& Wesseloo 2013) have shown the impact of seismic activity on ground support behaviour. Nevertheless, a lack of understanding remains about which seismic parameters must be assessed in order to design a dynamic ground support strategy that can mitigate seismic risk as the operation progresses. The objective of this paper is to quantify the influence on the performance and degradation of individual ground support elements of various seismic parameters, such as:

- Large seismic events.

- Number of seismic events. 
- Increase in apparent stress.

- The b-value from the Gutenberg-Richter frequency-magnitude relationship.

- Peak particle velocity.

- Energy radiated from a seismic event.

To meet this objective, a database and accompanying analysis tools were developed and then applied in a case study of the LaRonde mine (Quebec, Canada). Statistical relationships between selected factors and ground support demand at the back of excavations were derived, and the most significant ones are presented.

\section{Case study: LaRonde mine}

Located near the municipality of Preissac in the Abitibi-Témiscamingue region of Quebec, Canada, LaRonde mine is a world-class deposit of gold-copper and zinc-silver exploited along the Cadillac Fault (Figure 1). In production since 1988, LaRonde mine is currently operating at $3.1 \mathrm{~km}$ below the surface with a daily tonnage hoisted of 6,000 tonnes (Morissette 2017). Drilling is conducted at the mine site to convert approximately 1.2 million ounces of gold from mineral resources to mineral reserves between 3.1 and $3.5 \mathrm{~km}$ below surface (Agnico Eagle 2019). The conversion program is expected to continue in 2019 and will examine the continuity of the orebody at a depth of $3.7 \mathrm{~km}$. The mine is expected to operate until 2027.

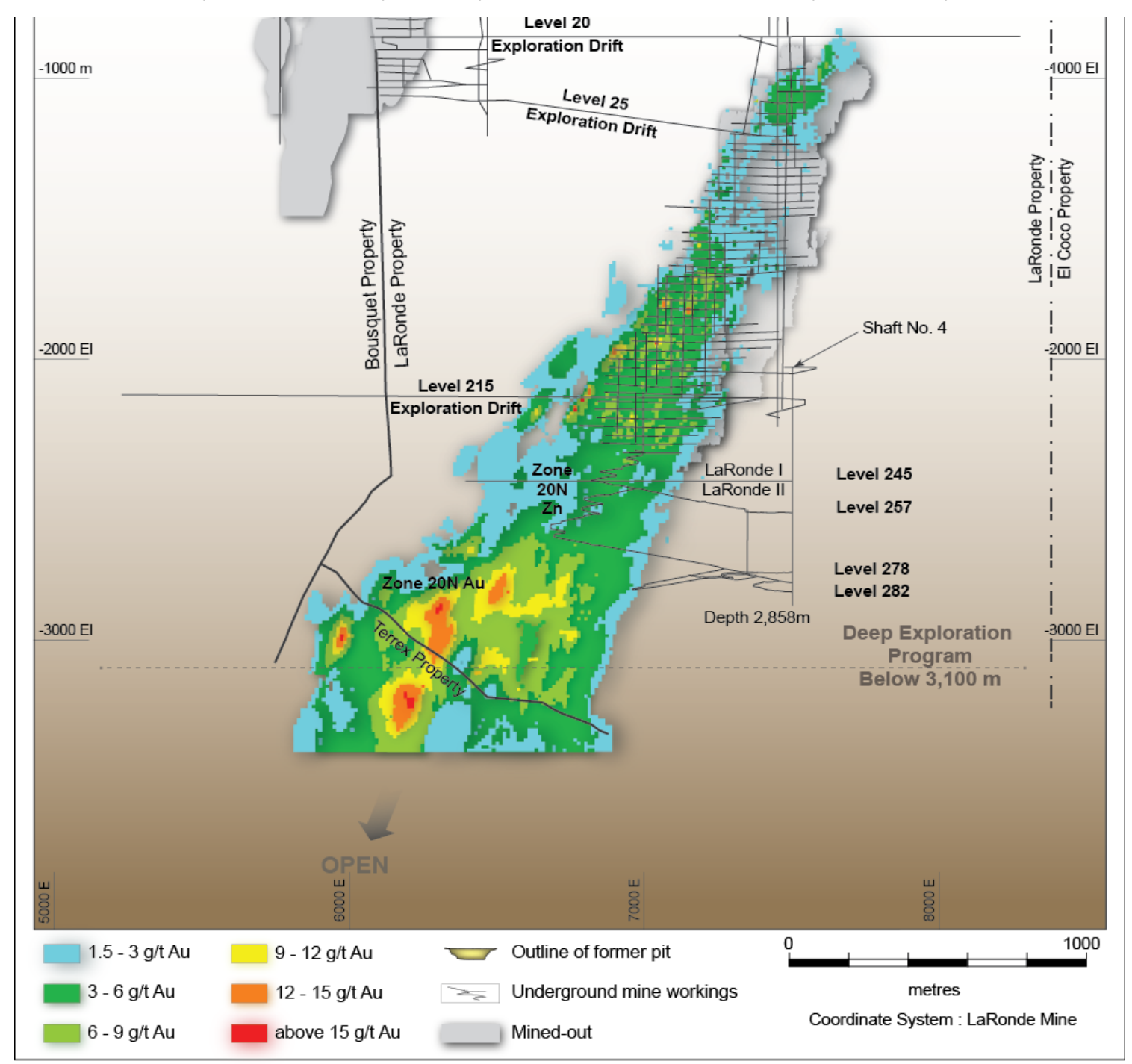

Figure 1 Longitudinal section of gold grades at the LaRonde mine (Morissette 2017) 
CANMET have measured the in situ stress at the site using stress cell measurement. The in situ principal major stress $\left(\sigma_{1}\right)$ is perpendicular to the orebody, the rock mass foliation, and the major faults (Table 1 ).

Table 1 Major principal stresses at LaRonde mine (CANMET 2000)

\begin{tabular}{ccc}
\hline Major principal stress & Orientation & Equation \\
\hline$\sigma_{1}$ & North-south & $1.62 \cdot \sigma_{\mathrm{v}}$ \\
$\sigma_{2}$ & East-west & $1.34 \cdot \sigma_{\mathrm{v}}$ \\
$\sigma_{3}=\sigma_{\mathrm{v}}$ & Vertical & $0.027 \mathrm{MPa} / \mathrm{m}$ \\
\hline
\end{tabular}

\section{Ground support at LaRonde mine}

\subsection{Ground support strategy}

Underground drift development at LaRonde mine faces a complex environment. At great depths, the presence of a strong regional foliation and high stress leads to squeezing conditions and significant seismicity. The ground support strategy aims to maintain the integrity of the excavations for both static and dynamic conditions. Experience gained at the site has shown that to manage the squeezing conditions, it is more efficient to install ground support in multiple stages.

Depending on the excavation type and historical seismic activity in the sector, the standard design (Figure 2) may vary. The three standard designs (DS, DG, and DD) used at LaRonde mine differ in terms of mesh (screen) height relative to the floor and the type and length of the ground support elements at the back of the excavation. The DS design is defined by mesh on the drift walls that terminates at a maximum distance of 6 feet $(1.8 \mathrm{~m})$ relative to the floor. Mesh for the DG and DD designs terminate at a maximum distance of 2 feet $(0.6 \mathrm{~m})$ relative to the floor to prevent unravelling of the lower part of the sidewalls.

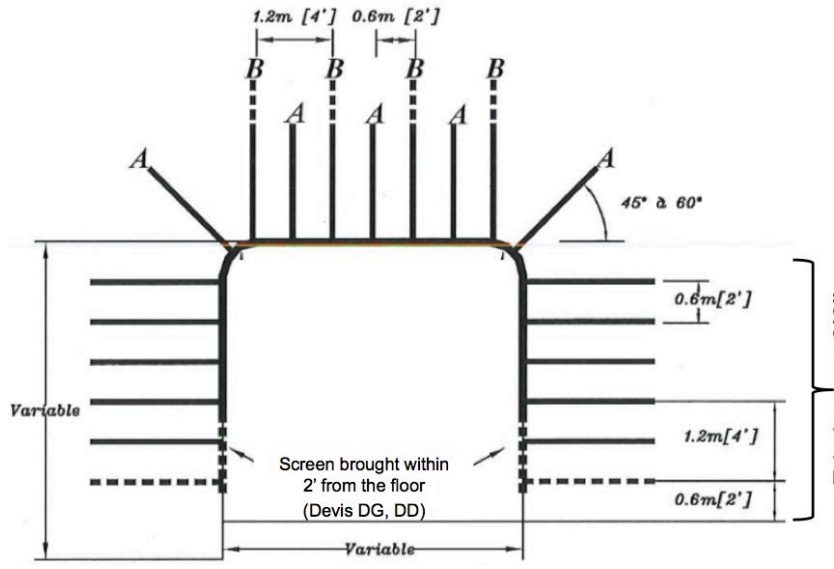

(a)

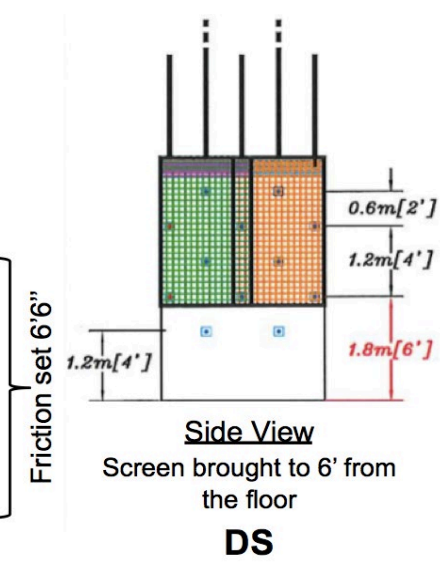

(b)

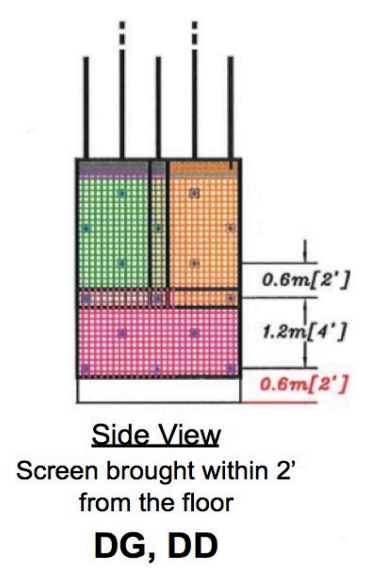

(b)

Figure 2 Section view (a) and side view (b) of the excavation ground support design at LaRonde mine for primary support installed after development blasting (LaRonde mine archive)

For all three standard designs, the ground support installed in excavation walls is always a friction set 6.5 feet $(2 \mathrm{~m})$ in length. However, the combination of ground support elements installed in the excavation back differs among the three designs (Table 2). Depending on the excavation span, intensity of rock mass fracturing and level of seismicity during development, the ground support design is adjusted by ground control personnel. Specifically, the reinforcement installed in Row B (Figure 2) is replaced with a bolt of longer anchoring length in larger span openings. The 6.2 foot $(1.9 \mathrm{~m})$ long, $7 / 8^{\prime \prime}$ threaded head rebar usually installed in Row B is replaced with a 9.5 foot $(2.9 \mathrm{~m})$ long, $3 / 4^{\prime \prime}$ forged head rebar in areas where the span is greater than $6.5 \mathrm{~m}$. 
The DD standard design consists of a dynamic reinforcement element (22 mm D-bolt) installed as part of Row $\mathrm{A}$, in place of the $1.8 \mathrm{~m}$ long rebar. This standard is applied in seismically active development headings.

Table 2 Ground support layout at the back of the excavation for three ground support standard designs

\begin{tabular}{lll}
\hline Design & Row A & Row B \\
\hline DS & Rebar 6'2" & Rebar 6'2" or rebar 9'6" \\
DG & Rebar 6'2" & Rebar 6'2" or rebar 9'6" \\
DD & D-bolt 7' & Rebar 6'2" or rebar 9'6" \\
\hline
\end{tabular}

For excavations that are likely to experience convergence conditions or seismicity, a secondary support consisting of hybrid bolts and mine straps is installed in the walls (Figure 3). Additional reinforcement elements in the walls take loads and reduce the overall total displacement in converging drifts (Karampinos 2016). Secondary support helps prevent extensive degradation of primary reinforcement in the back.

\section{Mine Strap with Hybrid bolt Mine Strap with Hybrid bolt}

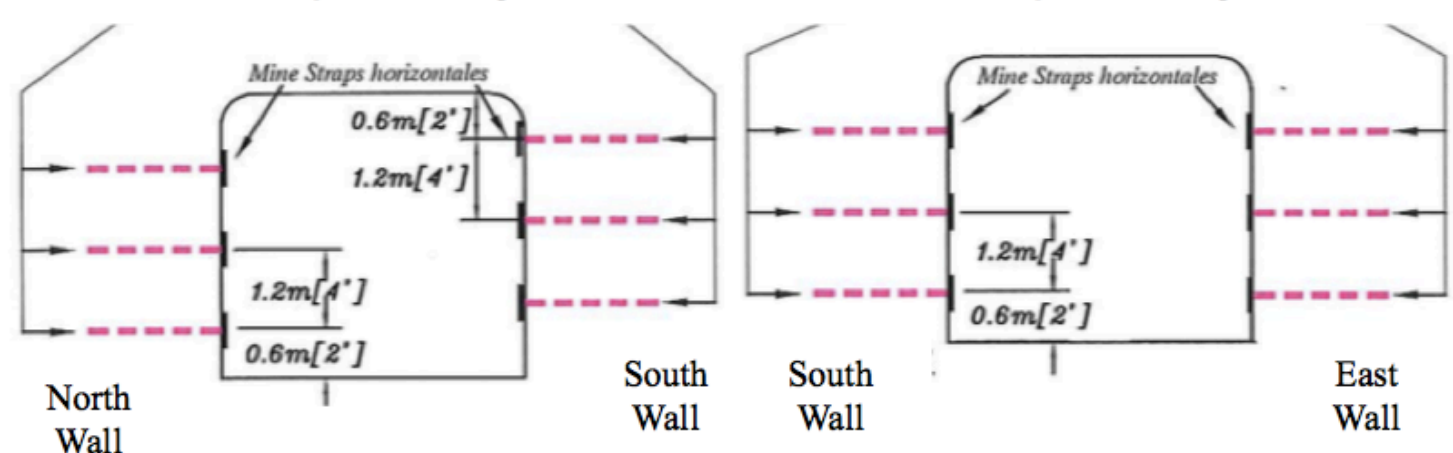

\section{$\mathrm{MH}$ (East-West Excavation Trend) $\quad \mathrm{MH}^{*}$ (North-South Excavation Trend)}

Figure 3 Side view of secondary support in the excavation sidewall; orientation is relative to the foliation (LaRonde mine archive)

Finally, tertiary support-typically consisting of 20 foot $(6.0 \mathrm{~m})$ long fully grouted bulged cable bolts, installed in conjunction with \#0-gauge mesh straps-is installed in the back as a function of span, orientation to the foliation, and excavation service life. Cable bolts are also installed in the walls in areas characterised by advanced convergence levels and subject to seismicity. Table 3 presents the capacity of the various ground support elements used at the mine for back reinforcement.

Table 3 Length and peak capacity of ground support elements installed at the back of excavations at LaRonde mine

\begin{tabular}{lcc}
\hline Ground support & Length (feet) & Capacity (tonnes) \\
\hline Cable & 20 & 26.5 \\
D-bolt & 7 & 23.5 \\
Rebar & 6.2 & 18.5 \\
Rebar & 9.6 & 18.9 \\
\hline
\end{tabular}




\subsection{Monitoring ground support performance and degradation}

Monitoring the performance and degradation of ground support elements is an integrated part of the LaRonde mine ground control program. Emphasis is placed on documenting visual observations of plate behaviours as indicators of loading on the bolts between the ramp and the drawpoints. Features of impacted ground support elements stored in the database include observation date, location and performance assessment. After visual inspection, reinforcement plates may be reported as intact, loaded or broken (Figure 4). As part of the LaRonde mine ground control program, all long-term excavations are inspected at least once per month for reporting on ground support degradation.

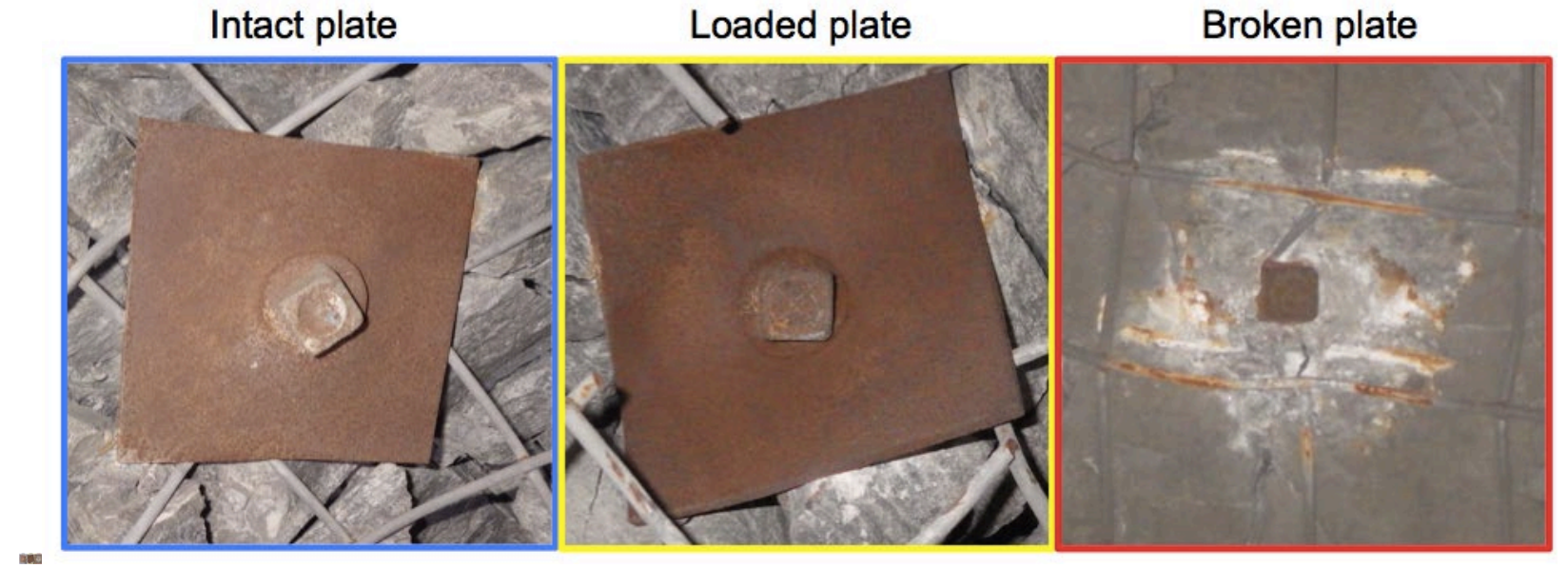

Figure 4 Three degradation levels reported after visual inspection of reinforcement element plates (LaRonde mine archive)

\subsection{Seismic monitoring at the mine site}

Since 2003, LaRonde mine has used seismic monitoring to detect the seismic response to mining. The monitoring system comprises 99 accelerometers with a frequency of $50 \mathrm{~Hz}(12$ triaxial and 87 uniaxial sensors) and seven $15 \mathrm{~Hz}$ geophones (Figure 5).

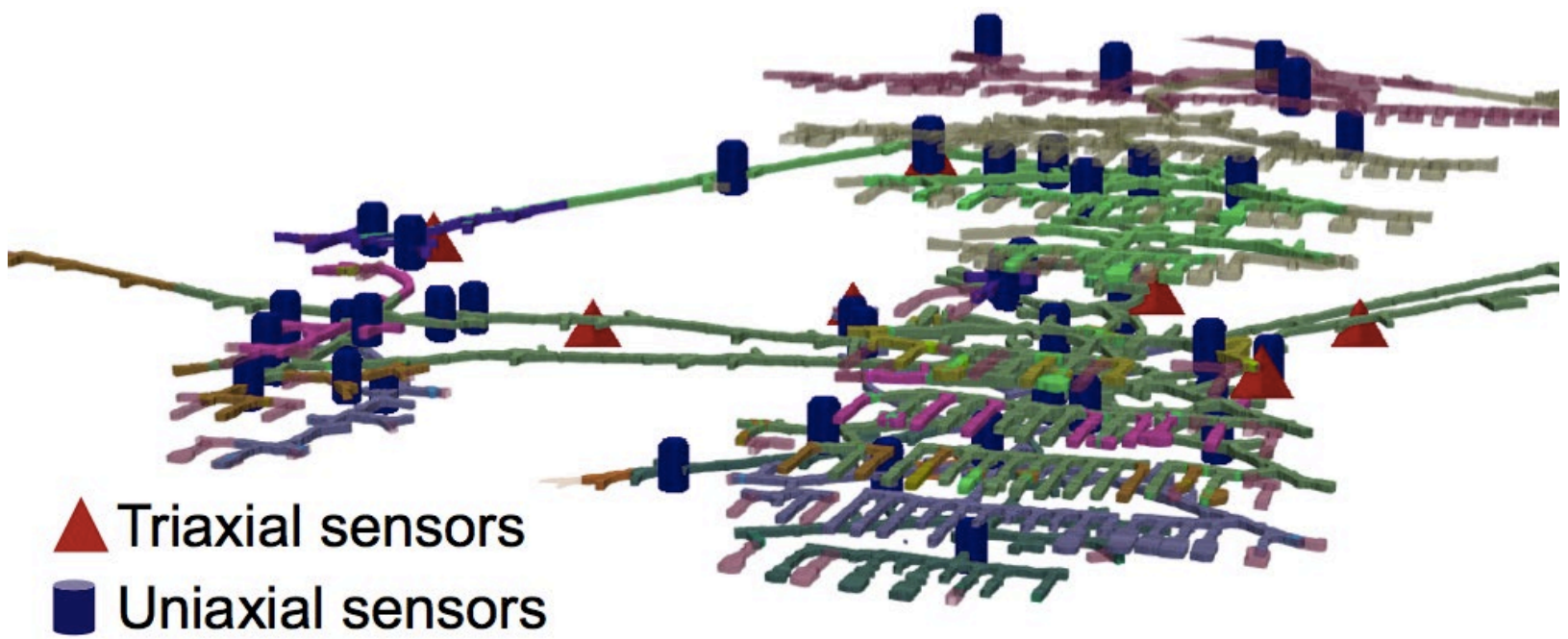

Figure 5 Arrangement of uniaxial and triaxial sensors at between 2,690 and 3,050 m depth at LaRonde mine

All seismic events recorded are processed by an acquisition system and then analysed and reviewed by members of the site engineering team. The seismic monitoring system localises and provides a series of quantitative assessments on seismic events, such as magnitude, moment, and energy ratio. Since its installation, the seismic system has become an essential tool to capture the evolution of the seismic risk as 
mining progresses (Brown \& Hudyma 2017) and to assess and mitigate seismic hazards by limiting exposure during times of increased hazard through the application of re-entry protocols (Vallejos \& McKinnon 2011).

\section{$4 \quad$ Methodology}

\subsection{Development of a database}

The methodology relies on segmentation of all mining drifts based on location and timing of development blasts. Seismic responses associated with drift developments were analysed. Since January 2014, more than 5,000 development blasts at LaRonde mine have been georeferenced in space and time by the engineering team. The drifts included in this analysis are located 2,690-3,050 m below surface, total more than $18.5 \mathrm{~km}$ in length and encompass eight development mine levels. Each segment is divided into 16 independent faces of equal size: the roof, floor and two walls of each segment are defined by four independent faces (Figure 6). On these faces, a wide range of parameters was assessed and stored.

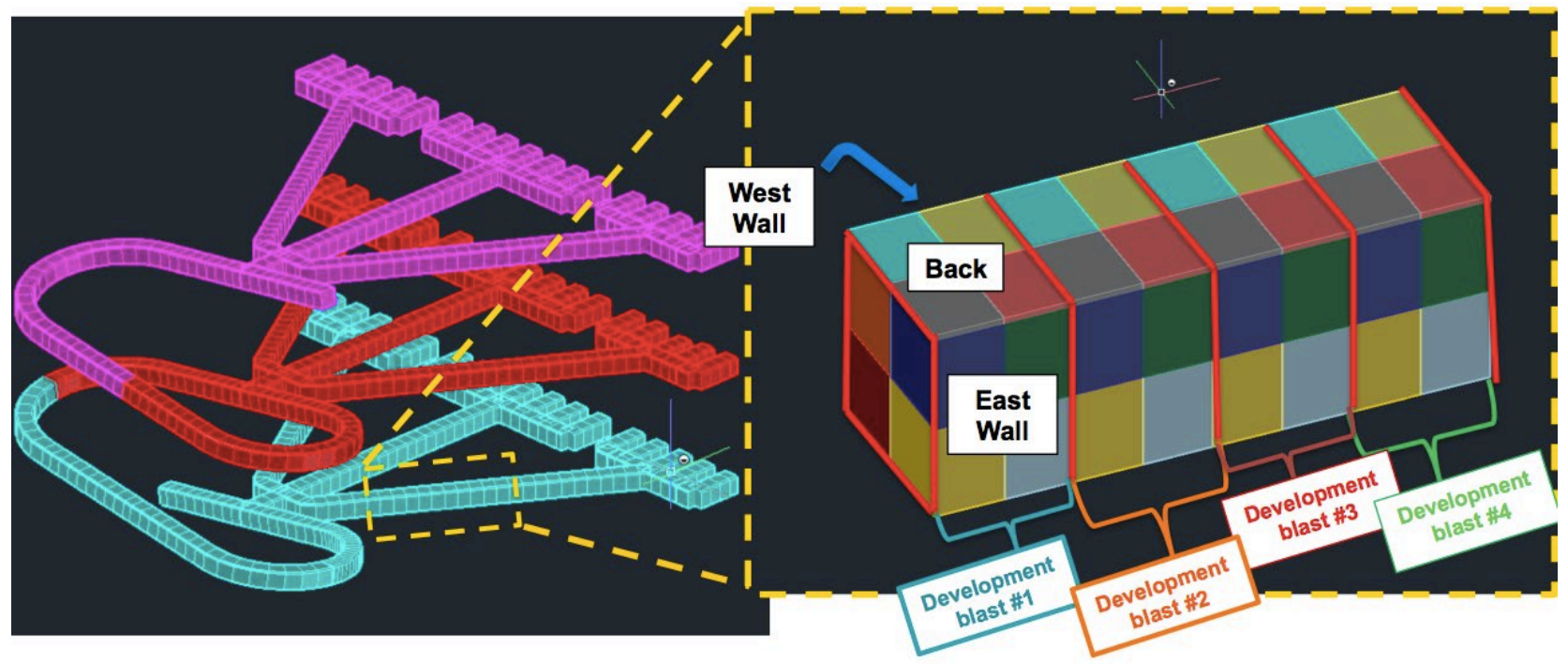

Figure 6 Three typical levels at LaRonde mine segmented with development blasts. Inset is the magnification of a drift section, showing 16 independent faces (Sasseville et al. 2019)

The database was populated from various sources of data to bring together a global history of ground support installed in drifts. For each face defined by development blasts, it includes:

- Installation date, loading capacity and location of installed ground support elements.

- Observation date, type of behaviour and location of ground support elements showing degradation.

- Time, location, magnitude, energy radiated, apparent stress, stress drop and energy ratio of seismic events.

\subsection{Spatiotemporal seismic filtering}

Spatiotemporal filtering was applied to all seismic events recorded at the site to provide a near-field seismic history associated with all development blasts at the site. Seismicity was only considered around a drift section after it was blasted. The selection included all seismic events that occurred within a radius of $22.5 \mathrm{~m}$ of the 1,215 development blasts (Figure 7). This radius was deemed an acceptable distance for a seismic event to impact ground support elements. The frequency-magnitude relation (Gutenberg \& Richter 1944) of the selected seismic events was performed to measure the sensitivity of the seismic monitoring system. The tail-off in the low magnitude portion indicates the seismic network sensitivity. Events lower 
than local magnitude -2.5 were recorded, but not consistently. Thus, an event local magnitude of -2.5 is the event minimum magnitude threshold.

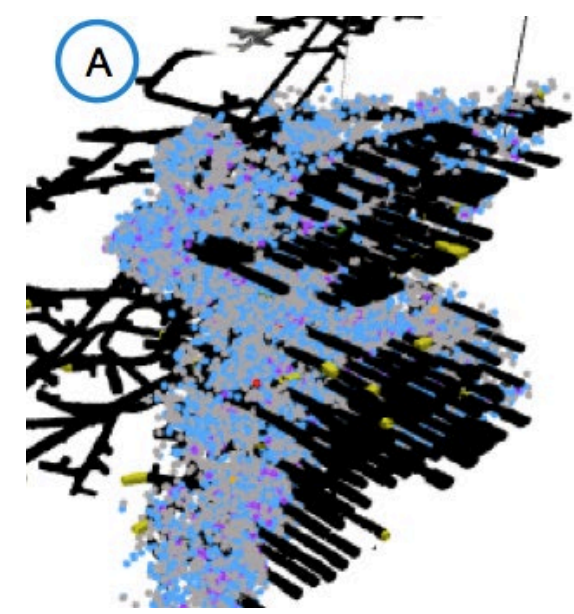

(a)

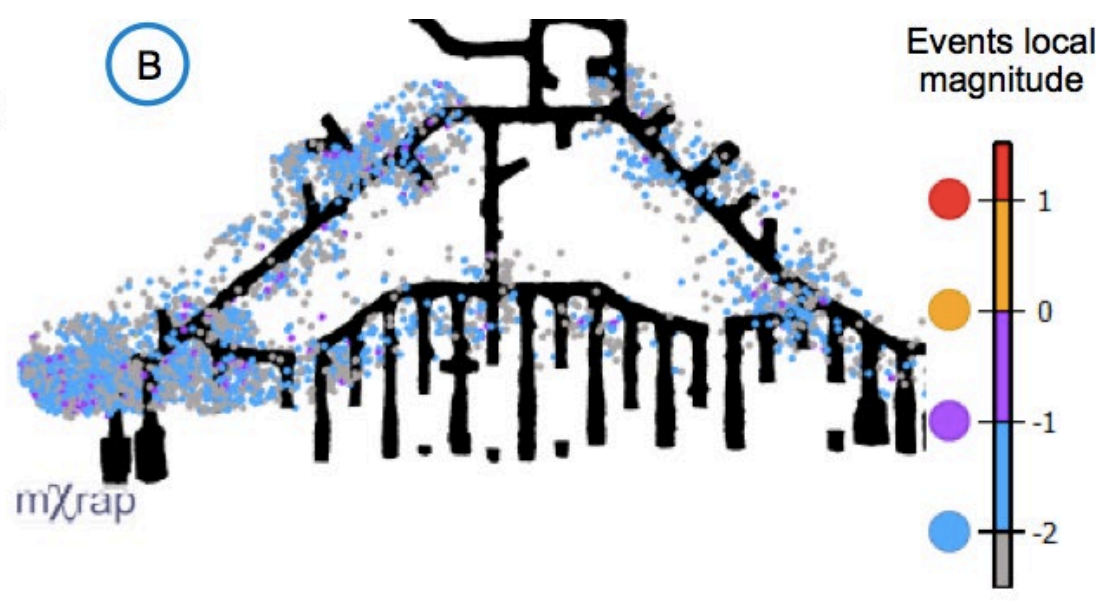

(b)

Figure 7 Seismic history for January 2014 to March 2018 within a radius of $22.5 \mathrm{~m}$ around excavations inspected monthly for (a) drift between 2,690 and 3,050 $\mathrm{m}$ depth, and (b) drift level 272 $(2,720 \mathrm{~m}$ below surface) at LaRonde mine since development blast was mined

\subsection{Seismic parameters studied}

\subsubsection{Seismic event rate}

Rock mass failure is commonly associated with multiple seismic events of different magnitudes occurring in confined areas where stress changes and geological conditions combine (Hudyma \& Potvin 2010). The seismic event rate will be assessed to identify patterns and precursory trends that may affect ground support demand.

\subsubsection{Local magnitude}

In practice, seismic events are typically used to infer information about the local rock mass failure based on parameters such as event magnitude. Regions within the rock mass that produce larger magnitude events typically correlate well with competent rock capable of storing large quantities of energy prior to failure (Brown \& Hudyma 2017). The energy released by the failure determines the size or intensity of a seismic event (Potvin 2009). Large events represent a high seismic hazard because they release a large amount of energy, which can be destructive. The local magnitude will be studied to identify patterns and precursory seismic trends that may affect the ground support demand.

\subsubsection{Peak particle velocity}

The peak particle velocity (PPV) is widely used in the mining industry for dynamic ground support design. The ground motion velocity represented by the PPV is used as a design parameter to capture the severity of the influence of the seismic event at a distance (Potvin \& Wesseloo 2013). The PPV takes into account the exponential attenuation of seismic wave intensity with distance from the source. According to Kaiser et al. (1996), the PPV is the most representative parameter to define the dynamic design load.

The Kaiser et al. (1996) and Kaiser \& Maloney (1997) charts are the most frequently used relationships. Based on the original far-field relationship proposed by Kaiser et al. (1996), Wesseloo (nd) suggested modifications to incorporate the saturation in the near field. Equations 1 and 2 present the Kaiser et al. (1996) equation with Wesseloo (nd) modifications for local magnitude. 


$$
p p v=\frac{C \times 10^{\frac{1}{2}\left(m_{L}+1.5\right)}}{R+R_{0}}
$$

where:

$$
\begin{aligned}
& C=0.2-0.3 \text { as recommended for design purposes } \\
& m_{L}=\text { local magnitude } \\
& R=\text { distance in metres } \\
& R_{0}=\text { source radius, estimated as follows (Kaiser et al. 1996): } \\
& \qquad R_{0}=\alpha \times 10^{\frac{1}{3}\left(m_{L}+1.5\right)}
\end{aligned}
$$

where:

$\alpha=0.53-1.14$

\section{$5 \quad$ Results}

\subsection{Ground support}

For mining operations exposed to dynamic conditions, it is important to identify the ground support elements that are degrading in order to rehabilitate critical locations or adjust the support design. According to Simser (2007), to withstand the dynamic loading generated during a seismic event, ground support must work as an integrated system; it will only be as strong as its weakest link. Thus, in a deep mine environment subjected to significant seismicity, identifying the degradation level of individual elements is an important process (Table 4). A degraded element can correspond to the weakest link of the chain. Support works as intended, until a threshold is reached. In the mining context, there is a high level of redundancy in the support system; therefore, failure of an element does not necessarily lead to system failure (Hadjigeorgiou 2016).

Table 4 Number of ground support elements degrading (loaded or broken) at the back of the excavation between July 2015 and February 2018 at 2,690-3,050 m depth

\begin{tabular}{lcc}
\hline Ground support type & Number of loaded element & Number of broken element \\
\hline Rebar 6'2" & 260 & 126 \\
Rebar 9'6" & 223 & 31 \\
Cable 20' & 93 & 16 \\
D-bolt 7' & 9 & 5 \\
Total & 585 & 178 \\
\hline
\end{tabular}

\subsection{Seismic history}

The magnitude-time history is a graphical technique used to assess the relationship between seismicity and change in the stress field due to mining or blasting (Hudyma \& Potvin 2010). The cumulative seismic event curve at the LaRonde mine is exponential throughout the study period (Figure 8), primarily because of blasting of the mining drift over time and progression of the mining sequence in the studied area. July 2015 corresponds to the first degraded reinforcement element identified between 2,690 and 3,050 m below surface. After this date, an exponential increase in the number of degraded ground supports was recorded. It could be argued that initial observation of degradation is associated with a shift in the cumulative 
number of events. Furthermore, the sudden increase in the number of degraded elements could be associated with an increase in large-magnitude events (above 0 after July 2016 and above 0.5 after July 2017).

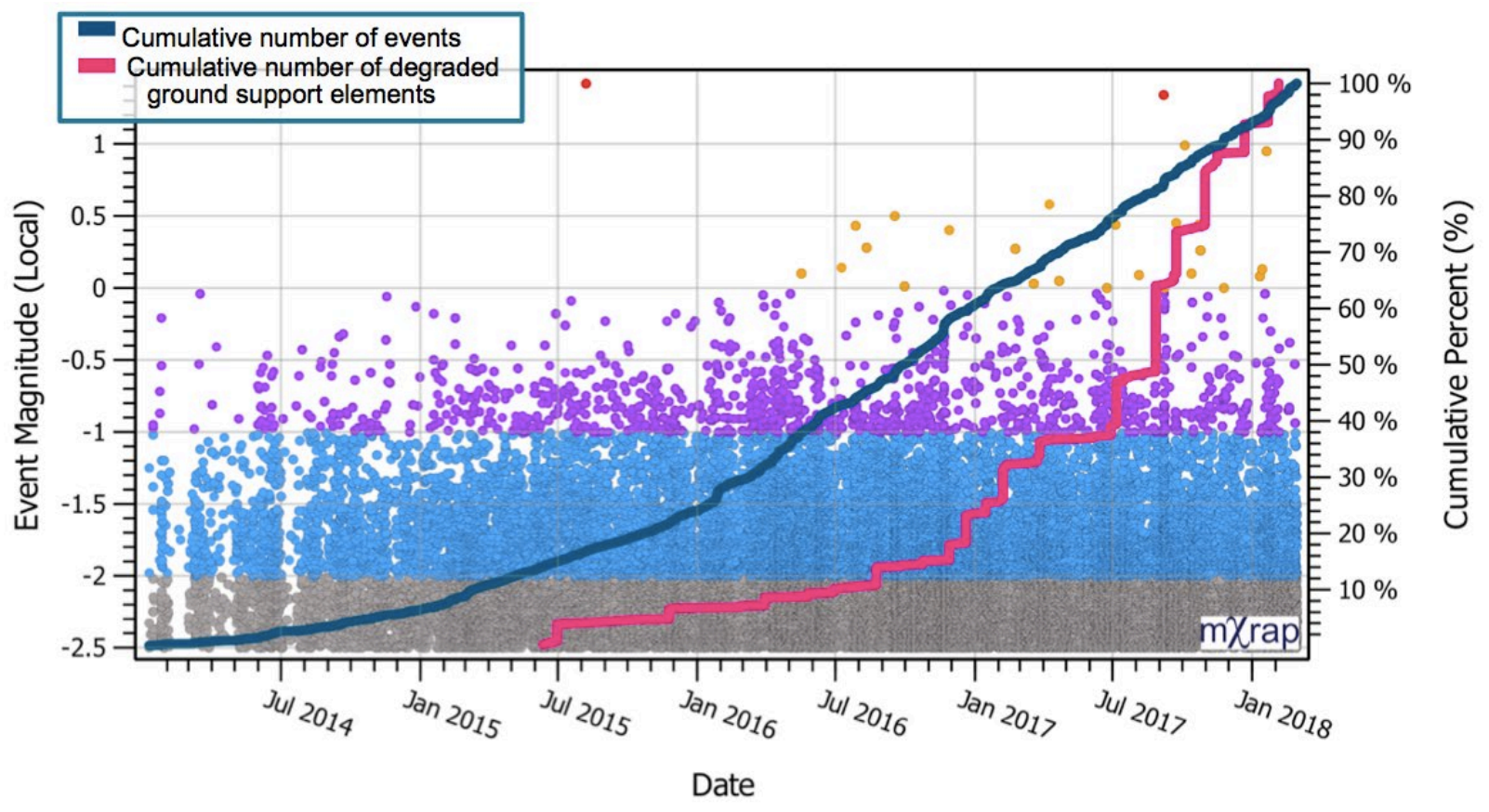

Figure 8 Magnitude-time history with the cumulative number of degraded ground support elements and number of events passing spatiotemporal seismic filtering at the LaRonde mine

\subsection{Seismic parameters}

Between July 2015 and February 2018, 763 reinforcing elements showed degradation (Table 4). Each element has a unique seismic history captured by spatiotemporal seismic filtering. The analysis consists of listing the daily seismic history around each degraded ground support element. For the sake of the analysis, all degradation observations are positioned at time zero. The 763 daily seismic records are superimposed on a timeline, and the maximum daily and monthly seismic parameter summations are computed for all degraded elements. This approach is consistent with the complete and systematic inspections of mine levels conducted on a monthly basis.

\subsection{Seismic rate}

The daily seismic history for the degrading ground support elements shows that the median number of events was constant over time (Figure 9[a]). A sudden peak of high amplitude was recorded before observing a degradation for percentile curves above the 95th percentile. This indicates that $5 \%$ of the degraded ground support elements at the site could be associated with a rise in seismic rate near the reinforcement element prior to degradation-in this case, a seismic rate above 15 events over a 24-hour period. This same analysis was performed with the monthly seismic history of the degraded ground support elements. A sudden peak of high amplitude was recorded before observing a degradation (Figure 9[d]). This increase indicates that $5 \%$ of the degraded elements at the site appear to be influenced by the number of seismic events. A seismicity rate higher than 125 events over a period of 30 days appears to be associated with seismic ground support degradation.

Arguably, the seismic event rate appears to be associated with the demand on ground support elements for $5 \%$ of all the observed degradations in the investigated zone. For the other degradation, the contribution of seismicity cannot be singled out. For these cases, parameters such as excavation geometry, structural conditions, reinforcement element corrosion, etc could also be critical factors. 


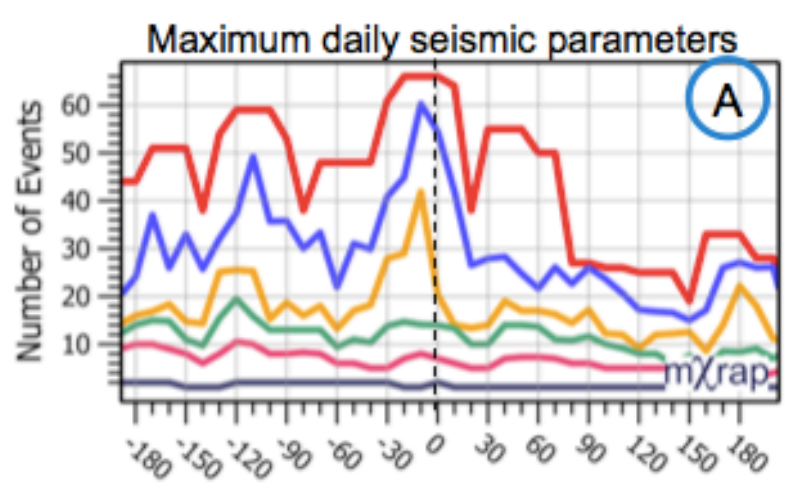

Days

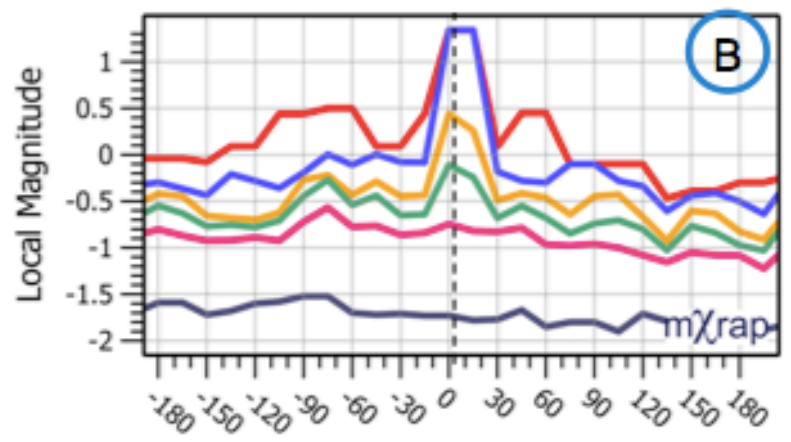

Days

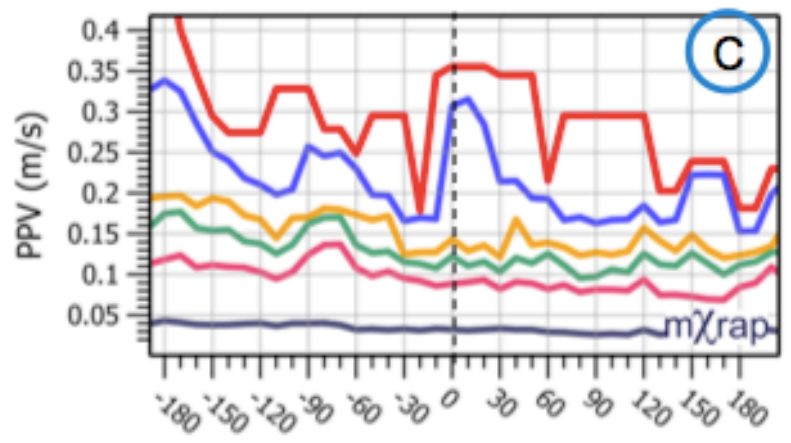

Days

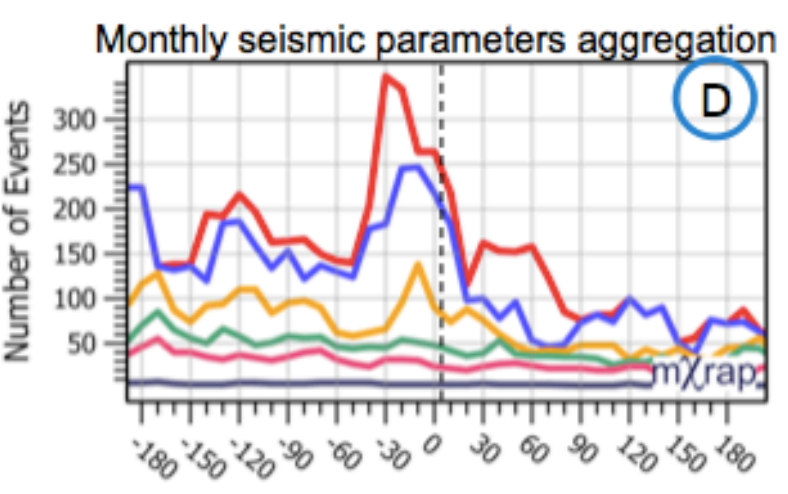

Days

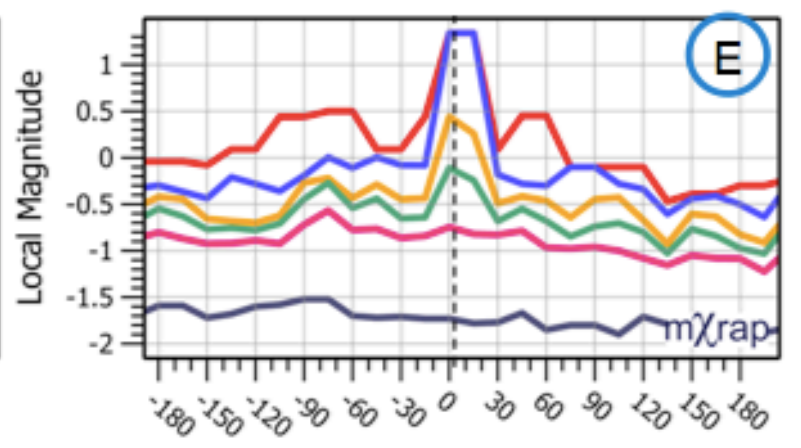

Days

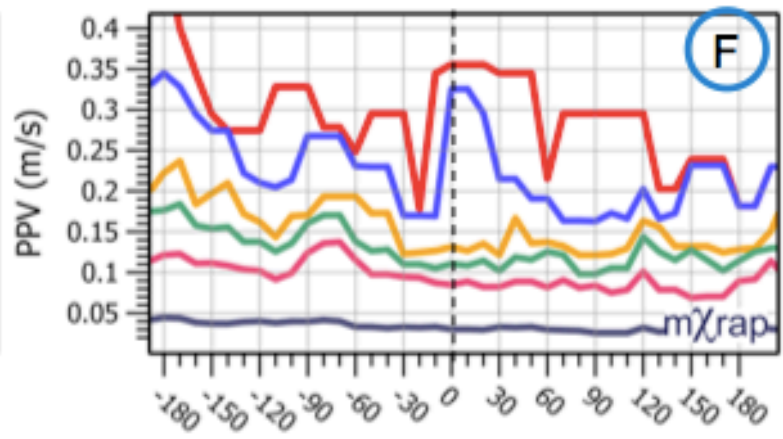

Days

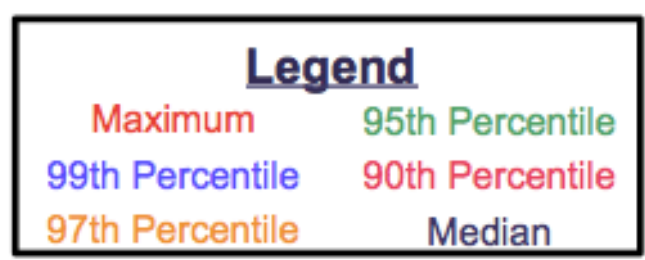

Figure 9 Maximum daily seismic parameter for (a) number of seismic events; (b) maximum local magnitude; (c) maximum peak particle velocity. Monthly seismic parameter for (d) number of seismic events; (e) maximum local magnitude; (f) maximum peak particle velocity

At LaRonde mine, an excavation will be subject to numerous seismic events during its service life. Analysis of the seismic history for all degraded reinforcement elements (Figure 10) shows that $60 \%$ of the ground support elements experience approximately the same number of seismic event before degradation is observed. However, when the number of seismic events exceeds 125, the curves become distinct. 


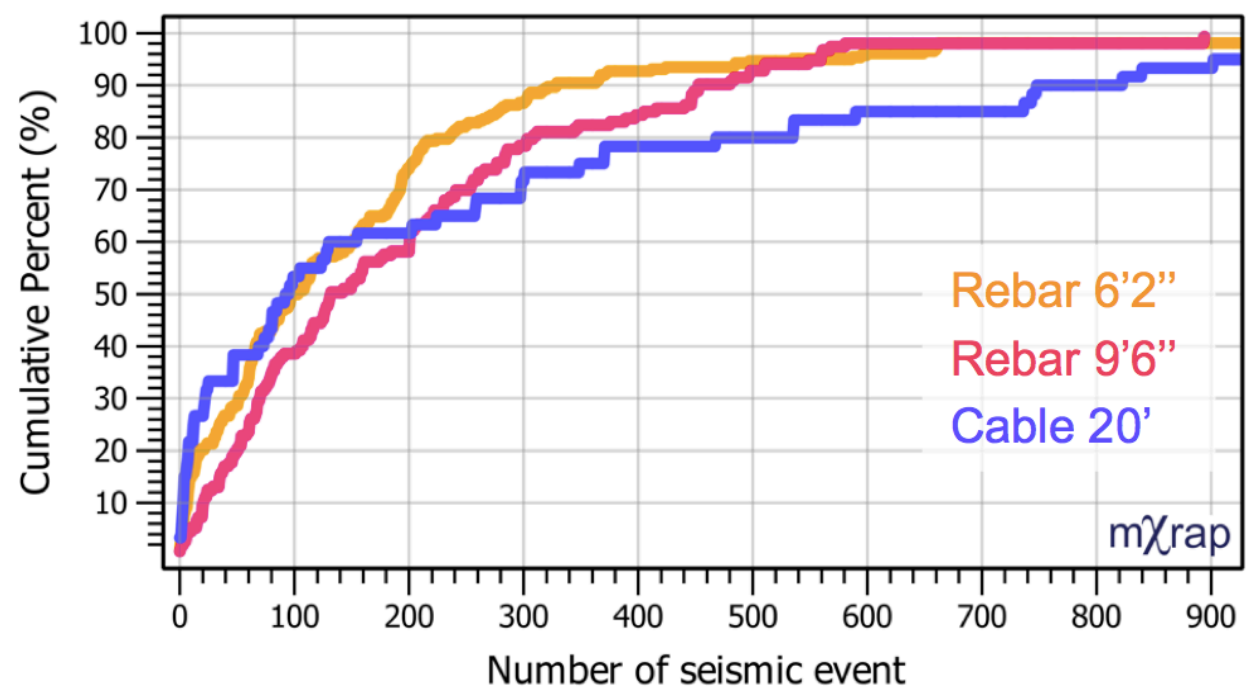

Figure 10 Cumulative distribution curve of the number of degraded ground support element related to the number of seismic events experienced before degradation was identified

Figure 9(d) shows that seismicity clearly affects element degradation when more than 125 monthly events (97th percentile) are recorded. Figure 10 shows that below a threshold of 125 cumulative events-below 125 monthly events - it is not possible to discern the impact of seismicity. Above that cumulative threshold, $20^{\prime}$ cables are degrading under a higher number of seismic events than the other inspected reinforcement elements. Conversely, the 6 ' 2 " rebar shows degradation under fewer seismic events compared with the other inspected reinforcement elements. Arguably, for element degradation clearly impacted by seismicity, cables can withstand a larger amount of seismic events than rebar can.

For excavations subject to significant seismicity, the LaRonde mine ground support strategy limits the installation of rebar by replacing rebar with D-bolts at the overlapping edges of the mesh sheet. Furthermore, in areas where seismicity can have a pronounced impact on the integrity of the ground support (e.g. intersections and development oriented parallel to the regional foliation), 20' cables are installed as secondary ground support. This practice allows the excavation to perform in a highly seismic environment and contributes to maintaining the integrity of the excavation over its service life.

\subsection{Local magnitude}

The maximum local magnitude was analysed daily for degraded ground support elements (Figures $9[\mathrm{~b}]$ ) and 9[e]). A sudden peak of high amplitude was recorded before observing degradation in ground support elements. This peak indicates that $10 \%$ of the ground support element degradations are controlled by the local magnitude of the seismic events. Furthermore, a seismic event with a local magnitude greater than -0.5 in a radius of $22.5 \mathrm{~m}$ from an excavation seems to affect rock reinforcement degradation.

When experiencing local magnitude events under -0.75 , the degraded ground support element will have approximately the same behaviour (Figure 11). Based on Figure 9(e), one could consider that above a magnitude of -0.5 (95th percentile curve) seismicity can be identified as a critical factor controlling element degradation. Figure 11 shows a clear shift in behaviour for ground support elements, undoubtedly controlled by seismicity. Over a local magnitude of $-0.75,20^{\prime}$ cables are able to sustain a greater number of high magnitude events than the other inspected reinforcement elements. Seismic events of a local magnitude greater than zero appear to have a significant influence on the load applied on cable bolts. Thus, $20^{\prime}$ cables installed at the site can perform well when subjected to seismic events with higher local magnitude. The ground support strategy applied at LaRonde mine involves the installation of cables in sectors that are prone to significant seismicity levels and more susceptible to severe long-term ground support degradation. 


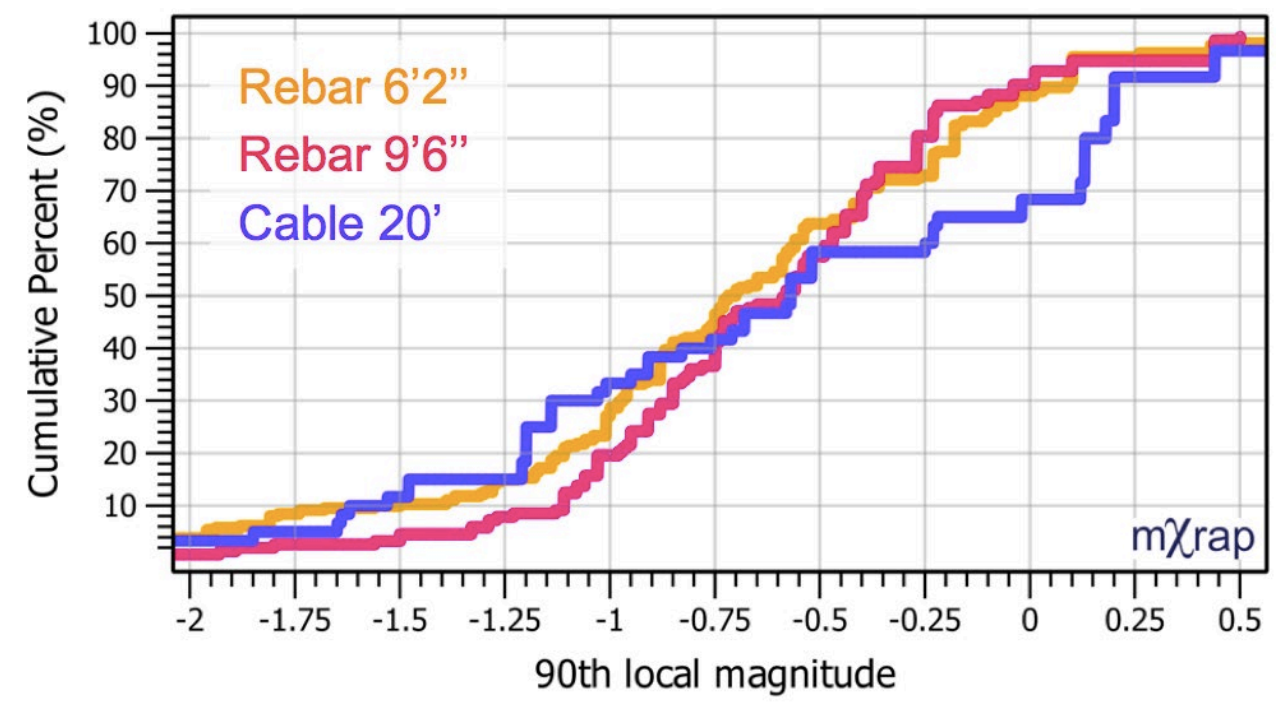

Figure 11 Distribution curve of the degradation of the ground support in relation to the local magnitude 90th percentile experienced before degradation has been identified

\subsection{Peak particle velocity}

The PPV was analysed daily for the degraded ground support elements (Figure 9[c]). A local peak was recorded before observing a degradation. However, other high peaks were evident in the months prior to observing degradation on ground support elements. Therefore, the PPV does not clearly influence the degradation of ground support elements at this site, which may be explained by the important limitations that influence this parameter and that must be taken into account. These limitations include the effect of geological features, lithology and mine voids on radiation and refraction of seismic waves (Morissette 2015; Potvin \& Wesseloo 2013). Also, the analysis was performed in a context of near-field condition. According to Potvin \& Wesseloo (2013), the near-field PPV is complex, non-uniform and not well understood. Further, investigation into this phenomenon is difficult due to the lack of reliable near-field data. The same type of conclusion may be derived for the other investigated parameters (graph not presented): the increase in apparent stress, the b-value from the Gutenberg-Richter frequency-magnitude relationship, and the energy radiated from the seismic event.

\section{Conclusion}

A database containing the complete ground support history at LaRonde mine (Quebec, Canada) was developed to identify patterns and precursory trends that may influence the performance and degradation on ground support elements. Key findings are that the seismic event rate and maximum seismic event magnitude are critical factors controlling the demand on ground support in some areas of the investigated drifts. Furthermore, the mine reinforcement strategy is efficient when seismicity is controlling reinforcement degradation. Another important finding is that the demand on ground support cannot entirely be explained by seismicity; other factors such as excavation geometry, structural conditions and reinforcement element corrosion could also be contributing. With these results, the site engineering team can continue to improve a support strategy to maintain the integrity of the excavations during their service lives.

\section{Acknowledgement}

The authors would like to acknowledge the financial support of the Fonds de Recherche du Québec Nature et technologies (FRQNT) and the collaboration of LaRonde mine and the Australian Centre for Geomechanics. 


\section{References}

Agnice Eagle, LaRonde Mine, Agnico Eagle, Toronto, viewed 17 September 2019, https://www.agnicoeagle.com/English/ operations-and-development-projects/operations/laronde/default.aspx

Brown, L \& Hudyma, M 2017, 'Identification of stress change within a rock mass through apparent stress of local seismic events', Rock Mechanics and Rock Engineering, vol. 50, no. 1, pp. 81-88.

CANMET 2000, unpublished notes, LaRonde mine.

Durrheim, J, Roberts, MKC, Haile, AT, Hagan, TO, Jager, AJ, Handley, MF, Spottiswoode, SM \& Ortlepp, WD 1998, 'Factors influencing the severity of rockburst damage in South African gold mines', Journal of the South African Institute of Mining and Metallurgy, vol. 98, no 2, pp. 53-57.

Gutenberg, B \& Richter, CF 1944, 'Frequency of earthquakes in California', Bulletin of the Seismological Society of America, vol. 34, no. 4, pp. 185-188.

Hadjigeorgiou, J 2016, 'Rock support: degradation and failure', in E Nordlund, T Jones \& A Eitzenberger (eds), Proceedings of the Eighth International Symposium on Ground Support in Mining and Underground Construction, Luleå University of Technology, Luleå.

Hadjigeorgiou, J \& Potvin, Y 2011, 'A critical assessment of dynamic rock reinforcement and support testing facilities', Rock Mechanics and Rock Engineering, vol. 44, no. 5, pp. 565-578, https://doi.org/10.1007/s00603-011-0155-4

Heal, D, Potvin, Y \& Hudyma, M 2006, 'Evaluating rockburst damage potential in underground mining', Proceedings of the 41st US Symposium on Rock Mechanics, American Rock Mechanics Association, Alexandria.

Hedley, DGF 1992, Rockburst Handbook for Ontario Hardrock Mines, CANMET special report SP92-1E.

Hudyma, M \& Potvin, Y 2010, 'An engineering approach to seismic risk management in hardrock mines', Rock Mechanics and Rock Engineering, vol. 43, no. 6, pp. 891-906.

Kaiser, PK, \& Cai, M 2012, 'Design of rock support system under rockburst condition', Journal of Rock Mechanics and Geotechnical Engineering, vol. 4, no. 3, pp. 215-227.

Kaiser, PK \& Maloney, S 1997, 'Scaling laws for the design of rock support', Pure and Applied Geophysics, vol. 150, no. 3-4, pp. 415-434.

Kaiser, PK, Tannant, DD \& McCreath, DR 1996, Canadian Rock Burst Support Handbook, Geomechanics Research Centre, Sudbury.

Karampinos, E 2016, Management of Squeezing Ground Conditions in Hard Rock Mines, doctoral dissertation, University of Toronto, Toronto.

Morissette, PNR 2015, A Ground Support Design Strategy for Deep Underground Mines Subjected to Dynamic-Loading Conditions, doctoral dissertation, University of Toronto, Toronto.

Morissette, P 2017, 'Pro-active strategies for mitigating the consequences of strainbursts at LaRonde mine', paper presented at the ACG Strainburst in Mining Seminar-How to Mitigate the Consequences, 10 October 2017, Sudbury.

Potvin, Y 2009, 'Strategies and tactics to control seismic risks in mines', Journal of the Southern African Institute of Mining and Metallurgy, vol. 109, no. 3, pp. 177-186.

Potvin, YH \& Wesseloo, J 2013, 'Towards an understanding of dynamic demand on ground support', in Y Potvin \& B Brady (eds), Proceedings of the Seventh International Symposium on Ground Support in Mining and Underground Construction, Australian Centre for Geomechanics, Perth, pp. 287-304.

Sasseville, G, Grenon, M \& Morissette, P 2019, 'Identification of critical factors contributing to increased demand on ground support elements at LaRonde mine', Proceedings of the 53rd US Rock Mechanics/Geomechanics Symposium, American Rock Mechanics Association, Alexandria.

Simser, BP 2007, 'The weakest link-ground support observations at some Canadian Shield hard rock mines', in Y Potvin (ed.), Proceedings of the 4th International Seminar on Deep and High Stress Mining, Australian Centre for Geomechanics, Perth, pp. 335-348.

Vallejos, JA \& McKinnon, SD 2011, 'Correlations between mining and seismicity for re-entry protocol development', International Journal of Rock Mechanics and Mining Sciences, vol. 48, no. 4, pp. 616-625.

Wesseloo, J (nd), Unpublished notes, Australian Centre for Geomechanics, Perth. 
